\title{
Discussion on Design of Flow Assurance for High Pour Point Crude Oil Transportation Pipeline
}

\author{
Li Pengcheng ${ }^{1}$, Lu Hong ${ }^{1}$, Chang Yonglei ${ }^{1}$, Wang Peiwei ${ }^{1}$, Li Gen ${ }^{2}$ \\ ${ }^{1}$ Department of Engineering Research and Design, CNOOC Research Institute Co., Ltd, Beijing, China \\ ${ }^{2}$ Department of Engineering, China University of Petroleum, Beijing, China
}

\section{Email address:}

lipch8@cnooc.com.cn (Li Pengcheng), luhong@enooc.com.cn (Lu Hong), changyl2@enooc.com.cn (Chang Yonglei), wangpw3@cnooc.com.cn (Wang Peiwei), lgjames@vip.qq.com (Li Gen)

\section{To cite this article:}

Li Pengcheng, Lu Hong, Chang Yonglei, Wang Peiwei, Li Gen. Discussion on Design of Flow Assurance for High Pour Point Crude Oil Transportation Pipeline. International Journal of Oil, Gas and Coal Engineering. Vol. 7, No. 2, 2019, pp. 47-51. doi: 10.11648/j.ogce.20190702.11

Received: January 28, 2019; Accepted: March 8, 2019; Published: April 2, 2019

\begin{abstract}
Flow assurance is very important for design and operation management of the high pour point crude oil transportation pipeline. This paper choose one oil pipeline of $\mathrm{CNOOC}$ as an analysis example. Research on two main design plan according to the thermal management mode. In the heating, hot water preheating and displacement plan, the best temperature of hot water is existed. Hot water $88^{\circ} \mathrm{C}$ will be adopted. The greater of the preheating water flowrate, benefits thepreheating. The design flowrate $6359 \mathrm{~m}^{3} / \mathrm{d}$ will be used. In skin effect electric heat plan, the pipeline insulation layer thickness of $80 \mathrm{~mm}$ and skin heating power of $2534 \mathrm{kw}$ will be used through technical economical comparison, and the advantage of skin effect electric heat plan is analyzed relative to heating, hot water preheating and the displacement plan. The above research results may provide technical reference for the future design of high pour point crude oil transportation pipeline.
\end{abstract}

Keywords: High Pour Point, SEHT, Displacement, Flow Assurance, Shutdown and Restart

\section{Introduction}

A newly oilfield developed by CNOOC has relatively poor crude oil properties with high wax content about $31.2 \%$ and high pour point $\left(45^{\circ} \mathrm{C}\right)$. It is a typical high pour point crude oil. The oil is collected from well field and then transported to the central processing plant. It is transported to the transfer station via a $47.8 \mathrm{~km}$ DN250 pipeline and then will be pumped into the oil pipeline network of Uganda. This pipeline is vital to the all oilfield development [1].

High pour point crude oil can't be transported in isothermal condition, usually by heating. The commission process of hot oil pipeline is the establishment of soil geothermal gradually. If the hot oil is directly put into production, when the hot oil just enters the cold pipeline whose temperature is equal to the natural temperature of the surrounding buried soil, the temperature difference between the crude oil and the soil is very large. Hence the cold pipeline will absorb a large amount of heat from the oil flow, so the oil temperature drops sharply. In order to avoid the occurrence of freezing blockage accidents, preheating must be carried out before the hot oil pipeline start-up [2].

When the crude oil is being transported, the minimum oil temperature should be higher than the pour point. As the pour point is higher than the surrounding soil temperature, the oil flow will cause heat loss under the influence of radial temperature difference. Once the flowrate is reduced to a certain extent, temperature of the crude oil along the pipeline will drop sharply and under the pour point. This may result in blockage. The minimum flowrate is defined to ensure flow normally in pipeline [3].

The crude oil temperature in the pipeline will drop because of planned or accidental shutdown. This will increase the viscosity of the crude oil, forming gelling structure, and resistance will increase significantly when restart. If the time of shutdown is too longer, the pressure required for restart may exceed the pump maximum head or the pipeline strength. Pipeline will not able to restart normally. Hence the shutdown time should be limited and take relative actions as soon as possible [4].

Above all, due to the influence of high pour point and the 
restriction of different operation owners for pipeline and transfer station. The preheat procedure, minimum allowable flowrate, shutdown and restart will be very vital in the design and operation management of high pour point crude oil pipeline.

Based on the thermal management mode, two design plans are proposed in research: (1) In normal transportation, crude oil is heated at the input of pipeline. Hot water is used for preheating and replacement. Named as heating, hot water preheating and replacement plan. (2) Skin effect electric heat tracing plan.

\section{Heating, Hot Water and Displacement Plan}

\subsection{Calculation of Safety Shutdown Time}

The shutdown includes the planned and accidental shutdown. If the time doesn't exceed the permitted after planned pipeline shutdown when equipment is maintained and other reasons. There is no need to take displacement measures for the crude oil in the pipeline; otherwise, heating or displacement measurement should be taken as far as possible.

To ensure the safety of pipeline, once the central processing plant or the pipeline occurs accidental shutdown due to unpredictable reasons. If the production cannot be resumed by preheating within the allowable time, crude oil must be displaced within the required time [5].

The safe shutdown time is defined as the time when the temperature of the crude oil drops to the pour point. Usually, the temperature at which the hot oil reaches the terminal is taken as the safe shutdown time to calculate the safe shutdown time of the pipeline. According to the simulation results, the safe shutdown time of the pipeline outlet temperature from $50^{\circ} \mathrm{C}$ to $45^{\circ} \mathrm{C}$ is about $14.5 \mathrm{~h}$.

\subsection{Pipeline Displacement and Preheating}

When the shutdown time exceeds the permitted, the operation procedure for the pipeline is as follows:(1)displace the crude oil with hot water;(2) Use hot water for preheating pipeline; (3) displace hot water with qualified crude oil;(4) the transfer station receive qualified crude oil.

Due to the restrictions of the pipeline and the transfer station belonging to different operation management owner, and the uncertain treatment capacity of waste oil and wastewater, according to the resource of preheating hot water, the following two preheating plans are proposed: (1) Preheating from central processing plant to the transfer station (regular pumping); (2) Preheating from the transfer station to central processing plant (reverse pumping).

\subsubsection{Regular Pumping Preheating}

Firstly, displace the oil with hot water in central processing plant. When the production is resumed, the pipeline is preheated by the central processing plant using hot water, and after reaching a certain preheating temperature the oil can be transported.

In the design of the plans, the following issues need to be considered:

(1) minimum flowrate for flow assurance

For the pipeline transporting high pour crude oil, the minimum temperature in theoutletis allowed to be higher than pour point by $3 \sim 5^{\circ} \mathrm{C}$, so the temperature in the transfer station should be high than $50^{\circ} \mathrm{C}$ (the pour point of the crude oil $45^{\circ} \mathrm{C}$ ). When the pipeline transport at minimum flowrate of $1182 \mathrm{~m}^{3} / \mathrm{d}$, as the calculation result of simulation, the minimum temperature of the pipeline inlet at central processing plant should higher than $84^{\circ} \mathrm{C}$. It's necessary to add heating facilities in the central processing plant and reform the heating system, and heat the crude oil $\left(68^{\circ} \mathrm{C}\right)$ from the tank to meet the process of heated oil transportation.

(2) The volume calculation of storage and transportation facilities at the transfer station

In the design of this plan, the thickness of wax deposition for the pipeline will be thick relatively due to its high pour point. The pig will not recommended to be applied between the oil-water interface in case of blocking during the process of displacement and commissioning. oil export pump is used as displacement pump to displace the crude oil with $77^{\circ} \mathrm{C}$ hot water in the central processing plant. As the calculation result of simulation, the amount of oily wastewater and hydrous waste oil received by the transfer station during the shutdown and restart process is shown in Table1.

Table 1. Wastewater and waste oil generated after shutdown.

\begin{tabular}{llll}
\hline Stage & $\begin{array}{l}\text { Volume } \\
\left(\mathbf{m}^{\mathbf{3}}\right)\end{array}$ & $\begin{array}{l}\text { Time } \\
(\mathbf{h})\end{array}$ & Note \\
\hline Displacement with hot water & 1479 & 5.42 & hydrous waste oil \\
Preheating (heat up to $\left.50^{\circ} \mathrm{C}\right)$ & 2767 & 11 & oily wastewater \\
Displacement with hot oil & 2256 & 8.33 & oily wastewater \\
Mixed section & 1000 & 43.66 & hydrous waste oil \\
\hline
\end{tabular}

It can be seen from the Table 1 that a $5000 \mathrm{~m}^{3}$ oily water tank and a $3000 \mathrm{~m}^{3}$ water-contaminated oil tank are required at the transfer station, Heating system should also be set in the water-contaminated oil tank. Water-contaminated oil can be transported back to the central processing plant by truck or treated by the transfer station self.

The advantage of this plan is that the central process plant has already set hot water resource, export pump, displacement pump and some other power equipment. The disadvantage is that facilities used for treating waste water and waste oil should be set in the transfer station. However the feasibility of such facilities being independently constructed by the pipeline owner at the transfer station and the supporting property of the operator of the transfer station cannot be determined at the design stage of this program.

\subsubsection{Reverse Pumping Preheating}

Reverse pumping preheating is that the crude oil at the transfer station is displaced with hot water to the central processing plant after shutdown. The hot water in the transfer 
station will be used for reverse pumping preheating to reach the temperature of commissioning after start-up. Finally, the hot water in the transfer station will be displaced with hot oil in the pipeline.

In the design of plan, the following issues need to be considered:

(1) The minimum flowrate for flowing assurance

In this plan, not only the temperature in the transfer station should be higher than $50^{\circ} \mathrm{C}$ to guarantee the regular pumping, but also the minimum temperature of the central processing plant is higher than $50^{\circ} \mathrm{C}$ during the reverse pumping. It's assumed that the pipeline operate at the maximum flowrate, the temperature of the transfer station should be higher than $52^{\circ} \mathrm{C}$ as the simulation shows. When the crude oil is transported at $1182 \mathrm{~m}^{3} / \mathrm{d}$, the temperature at the central processing plant should be higher than $90^{\circ} \mathrm{C}$, which is higher than regular pumping by $6^{\circ} \mathrm{C}$. It's also necessary to add heating facilities in the central processing plant and reform the heating system, and heat the crude oil $\left(68^{\circ} \mathrm{C}\right)$ from the tank to meet the process of heated oil transportation.

(2) Determination of the temperature of the preheated hot water

The preheating is assumed to be done at $6359 \mathrm{~m}^{3} / \mathrm{d}$, which is the maximum flowrate of the pipeline. After temperature at the central processing plant reaching $50^{\circ} \mathrm{C}$, the time and the total amount of water required for preheating versus preheated water temperature is shown in Figure 1.

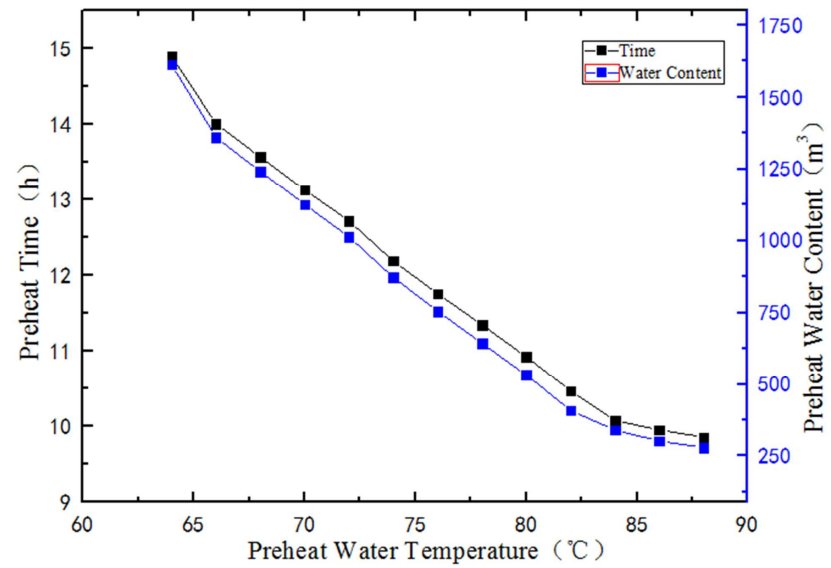

Figure 1. The required time and water content for preheating versus preheated water temperature.

As the above picture shows, as the increase of the temperature of preheated water, the amount of hot water and the time required for preheating both reduced. When the temperature is higher than $84^{\circ} \mathrm{C}$, the relationship is relatively getting flat. Hence the temperature of the preheated water is recommended to be $84^{\circ} \mathrm{C}$.

(3) Determination of the preheated water flowrate

The preheating is assumed to be done at $84^{\circ} \mathrm{C}$. After the temperature of the central processing plant reaching $50^{\circ} \mathrm{C}$, the time and the total amount of water required for preheating versus preheated water flowrate is shown in Figure 2.

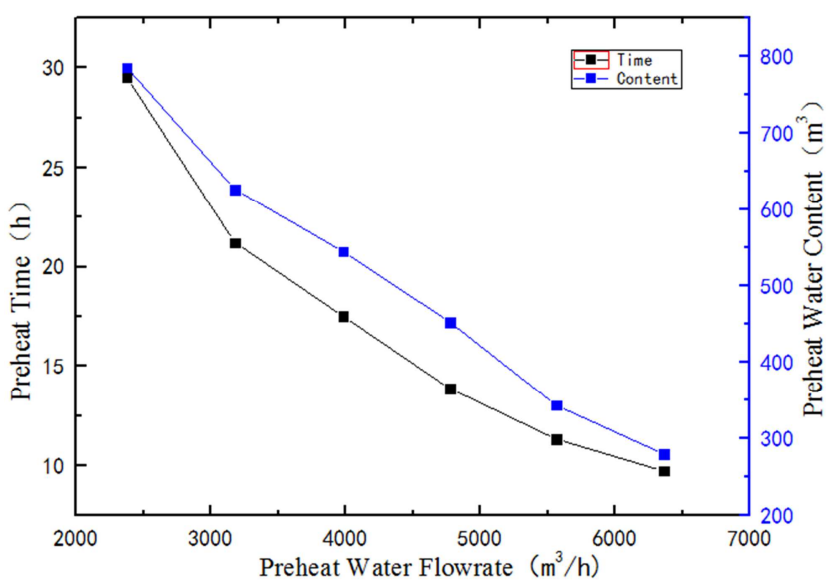

Figure 2. The required time and water content for preheating versus preheated water flowrate.

As the above figures shown, the consumption of the preheated water and the preheating time are reduced with the increase of the flowrate. Therefore, the flowrate should be as great as possible under the permitted of process conditions. Because of the fact that there is no data of the export pump located at the transfer station, the design flowrate is assumed.

(4) Determination of the temperature of reverse pumping

The oil will be put into reverse at transfer station when the preheating of the pipeline finished. It's assumed that the flowrate of the commissioning is $6359 \mathrm{~m}^{3} / \mathrm{d}$, and the oil is the same with the original crude oil. To make sure that the temperature of the oil that reach the central processing plant firstly and back to the transfer station is still higher than $50^{\circ} \mathrm{C}$, the temperature at the transfer station when begin to do reverse pumping should be higher than $64^{\circ} \mathrm{C}$ as the simulation shows.

The advantage of this plan is that there is no need to set storage and transportation facilities for processing wastewater and waste oil. Crude oil and wastewater after displacement are all qualified by the central treatment plant; the disadvantage is that the central processing plant needs to heat the crude oil to a higher temperature. The crude oil and hot water needed for displacement are supplied by the transfer station, which is highly restricted by the oil transfer operation.

Both regular pumping and reverse pumping are needed to equipped with a heat facility at the central processing plant to ensure flow assurance. Moreover, preheating and displacement plan is complicated. The dependence on the gas station is large, and this plan is not flexible enough, but the overall investment is relatively lower.

\section{Skin Effect Electric Heat Tracing Plan}

Skin effect electric heat tracing plan means that the pipeline is used as electric resister to generate heat, utilizing the skin effect and proximity effect. When alternating current is applied to the heat pipeline and the $\mathrm{T}$ cables, the current between the $\mathrm{T}$ cables and the heat pipeline is mutually induced, 
causing the current returned in the heat pipe to collect on the inner surface of the heat pipe. Under the effect of skin, pipeline will generate high-efficient heat. Under the proximity effect, pipeline form a reliable physical insulation, and there is no measurable current on the outer surface of the heat pipe [6-7].

To make sure that the crude oil can be transported normally under a certain flowrate, the most important appliance of the skin effect is to calculate the heat power [8].

(1) The heat power of normal transportation

To make the temperature of oil at the transfer station higher than $50^{\circ} \mathrm{C}$ with the minimum flowrate of $6359 \mathrm{~m}^{3} / \mathrm{d}$, the power should be higher than $650 \mathrm{KW}$ as the calculation of simulation according to the skin effect.

(2) The heat power of shutdown and restart

When the pipeline are shutdown, the crude oil in the pipeline will eventually drop to the surrounding temperature of $25.5^{\circ} \mathrm{C}$ due to heat loss. The crude oil in the pipeline will form the gelling structure. Therefore, the crude oil should be heated to a certain temperature before restart [9].

For safety reasons, the temperature of restarting is set to be $80^{\circ} \mathrm{C}$ which is the dissolved wax point of the crude oil. In order to determine the reasonable insulation thickness and the setting of the skin effect system, the economics of each plan are compared when the thickness of insulation is $50 \mathrm{~mm}$ and $80 \mathrm{~mm}$ respectively. The results are shown in Table 2.

Table 2. Economic comparison between different insulation thicknesses.

\begin{tabular}{|c|c|c|c|c|c|c|c|}
\hline $\begin{array}{l}\text { Thickness of } \\
\text { insulation } \\
(\mathrm{mm})\end{array}$ & $\begin{array}{l}\text { The time of } \\
\text { heating (h) }\end{array}$ & $\begin{array}{l}\text { The number of } \\
\text { power }\end{array}$ & $\begin{array}{l}\text { The ratio of } \\
\text { heat tracing }\end{array}$ & $\begin{array}{l}\text { Heating load } \\
(\mathrm{Kw})\end{array}$ & $\begin{array}{l}\text { Investment cost } \\
\text { (Ten thousand } \\
\text { yuan) }\end{array}$ & $\begin{array}{l}\text { Increasing cost due } \\
\text { to insulation (Ten } \\
\text { thousand yuan) }\end{array}$ & $\begin{array}{l}\text { The total cost } \\
\text { (Ten thousand } \\
\text { yuan) }\end{array}$ \\
\hline \multirow{3}{*}{50} & 48 & 2 & $1: 3$ & 4050 & 5540 & 0 & 5540 \\
\hline & 72 & 2 & $1: 3$ & 3263 & 5540 & 0 & 5540 \\
\hline & 96 & 2 & $1: 3$ & 3121 & 5540 & 0 & 5540 \\
\hline \multirow{3}{*}{80} & 48 & 2 & $1: 3$ & 3315 & 5540 & 478 & 6018 \\
\hline & 72 & 2 & $1: 2$ & 2534 & 3730 & 478 & 4208 \\
\hline & 96 & 2 & $1: 2$ & 2055 & 3730 & 478 & 4208 \\
\hline
\end{tabular}

As above table shown, the thickness is suggested to be $80 \mathrm{~mm}$, and the heating power of the skin heating system is set to $2534 \mathrm{~kW}$, which ensures that the temperature of crude oil buried raises to $80^{\circ} \mathrm{C}$ within $72 \mathrm{~h}$ at surrounding temperature of $25.5^{\circ} \mathrm{C}$ after a long period of shutdown,.

Compared with displacement plan, the skin effect electric heat plan has the following advantages [10]:

(1) Under normal operating condition, the skin effect electric heat plan can reduce the sensitivity of the pipeline system to the flowrate, control the delivery temperature of the out-transfer pipeline, change the fluid flow priorities, and ensure that the fluid temperature in the pipeline is always above the waxing point;

(2) Under the planned shutdown or accidental, the pipeline temperature can be stabilized above the safe temperature to increase the no operating time and cooling time;

(3) When restarting after a longtime shutdown, the pipeline cooled to surrounding temperature can be preheated without considering other preheating measures;

(4) The interface with other operating units is clear, the dependence is low, and the production plan is relatively flexible.

\section{Conclusion}

The preheating procedure, minimum allowable flowrate, shutdown and restart up are the key flow assurance issues for design and operation management of the high pour point crude oil transportation pipeline. The displacement development can be divided regular and reverse pumping based on the direction of the displacement. The preferential development is selected considering factors such as the preheated water source, storage and transportation facilities, and ownership relationship between the pipeline and the crude oil transfer station.

The amount of hot water and the time of preheating will be reduced with the increase of the temperature of preheated water. However, when the temperature is greater than a certain temperature, the change is relatively flat, so there is an optimal preheating temperature. The consumption of preheating water and preheating time will be reduced with the increase of preheating flowrate. The flowrate is advised as great as possible under the permitted of process conditions.

The power of skin effect electric heat tracing development should be optimized by comprehensive economic and technical factors. Such as crude oil properties, surrounding temperature, pipeline characteristics, preheating time requirements and soon.

The skin effect electric heat tracing development can reduce the flowrate sensitivity for pipeline system compared with displacement development. It can ensure that the fluid temperature is always above the pour point in the pipeline. The pipeline is allowed to cool down to ground surrounding temperature after a longtime shutdown without considering other preheating measures.

\section{References}

[1] Xu Yuhang, Hu Wenjie, and Bai Shutong, Selection and research of a high-condensation and high-wax crude oil pipeline process abroad [J]. Inner Mongolia Petrochemical, 2013, 7:4 7.

[2] Chen Hongju, Zhou Xiaohong. Submarine Pipeline Transportation Process in Regional Development [J]. Petroleum Planning and Design, 2011, 22(4): 30-33. 
[3] Chen Hongju, Zhou Xiaohong, Wang Jun. Discussion on the design of flow safety protection for deep water natural gas pipeline [J]. China Offshore Oil and Gas, 2011, 23(2): 122-125.

[4] Yang Xiaoheng. Design and Management of Oil Pipeline [M]. Dongying: China University of Petroleum Press, 2006: 251-253.

[5] An Weijie. Offshore Oil Engineering Design Guide [M]. Beijing: Petroleum Industry Press, 2007: 31-33.

[6] Nie Yongchen, Zhang Lei, An Shaogang, et al. Prediction of waxing regularity of high-condensation crude oil pipeline in Qinghai Oilfield [J]. Oil \& Gas Field Engineering, 2017, 36(1): 11-14.

[7] Guo Xiucui. Application of the skin effect electric heating of submarine pipeline in the oil and gas fields of southern Anhui Province [J]. China Offshore Oil and Gas (Engineering), 2003, 15(2): 20-23.

[8] Fu Lei, Li Wenbin, Zhang Xueteng. Application of built-in skin effect electric heat tracing technology in oil collection system [J]. Oil and Gas Field Surface Engineering, 2016, 35(10): 58-61.

[9] Wang Weiqiang, Wu Ming, Zhang Jing. Application Prospect of Electric Heat Tracing Technology in Crude Oil Transportation [J]. Oil and Gas Field Surface Engineering, 2004, 23 (8):26.

[10] Wang Dong. Comparative Analysis of Active Heating Technology for Deepwater Submarine Pipeline [J]. Petrochemical Equipment, 2016, 45(3): 64-68. 